\title{
Effect of friction welding parameters on the tensile strength and microstructural properties of dissimilar AISI 1020-ASTM A536 joints
}

\author{
Radosław Winiczenko ${ }^{1}$
}

Received: 23 March 2015 / Accepted: 24 August 2015 /Published online: 5 September 2015

(C) The Author(s) 2015. This article is published with open access at Springerlink.com

\begin{abstract}
This paper presents an effect of friction welding parameters on the tensile strength and microstructural properties of dissimilar AISI 1020-ASTM A536 joints. A hybrid response surface methodology (RSM) and genetic algorithm (GA)-based technique were successfully developed to model, simulate, and optimise the welding parameters. Direct and interaction effects of process parameters on the ultimate tensile strength (UTS) were studied by plotting graphs. Friction force and friction time have a positive effect on tensile strength. As friction force and friction time increase, the tensile strength also increases. The maximum tensile strength of the friction-welded low carbon steel-ductile iron joints was $87 \%$ of that of the base metal. The tensile properties, microstructure, Vickers hardness distribution, and fracture morphology of the welded specimen have been studied and presented in this study. Additionally, the distribution of carbon element on both sides of the interface was estimated using energydispersive spectroscopy (EDS). The results of the metallographic study show clearly that the friction welding process was accompanied by a diffusion of carbon atoms from ductile iron to steel. This process causes the formation of a carbonrich zone at the interface and decarburization zone in the ductile iron close to the bond interface.
\end{abstract}

Keywords Friction welding - Ductile iron - Low carbon steel · Genetic algorithm · Tensile strength $\cdot$ Microstructure · Optimisation

Radosław Winiczenko

radoslaw_winiczenko@sggw.pl; rwinicze@poczta.onet.pl

1 Department of Production Engineering, Warsaw University of Life Sciences, Nowoursynowska 166, 02-787 Warsaw, Poland

\section{Introduction}

Ductile iron castings are used for many structural applications, particularly those requiring strength and toughness combined with good machinability and low cost. There are applications such as crankshafts, steering knuckles, differential carriers, brake callipers, hubs, brackets, valves, water pipes and many others $[1,2]$. Special materials and techniques are available for the repair welding of ductile iron castings or for joining ductile iron to itself or to other ferrous materials, such as mild steel, austenitic steel, and grey, nodular or malleable iron [3]. These methods include manual metal arc welding, flux cored arc welding, metal inert gas welding, gas tungsten arc welding, gas welding, diffusion bonding, impact-electric current discharge joining, laser welding, oxyacetylene powder welding, rotary friction welding and friction stir welding [4].

Ductile irons contain higher amounts of carbon compared to steels which diffuse into the austenite during welding, forming hard brittle phases at the weld interface, namely martensite and carbides. These give rise to poor elongation properties and high hardness values, as reported by Pascual et al. [5]. Therefore, like the welding of other cast irons, the welding of ductile iron requires special precautions to obtain optimum properties in the weld metal and adjacent heat-affected zone (HAZ) [6]. The main objective is to avoid the formation of cementite in the matrix material, which makes the welded region brittle, but in ductile iron, an additional objective is of almost equal importance, concerning the retention of a nodular form of graphite [7].

Friction welding (FW) is suitable in the case of materials for which conventional welding is either very difficult or even impossible [2]. Therefore, in recent years, ductile iron has been successfully friction welded and also joined to other materials, such as steels with a high alloy content. According to Crossland [8], the main reasons for dissimilar joining are 
due to the combination of good mechanical properties of one material and the low specific weight, good corrosion resistance and good electrical properties of the other material. However, according to the American Welding Society (AWS) [9] and Lebedev and Charnenko [10], the friction welding of ductile iron is not possible because graphite acts as a lubricant and prevents the generation of heat sufficient for joining. Hence, many researchers conducted a study on the combination of low carbon steel (LCS) and ductile iron (DI). However, ductile iron-steel welded joints are particularly difficult to produce since carburization takes place on the LCS side with carbide formation. This can result in the formation of a brittle, hard zone that cannot be eliminated by annealing [11]. Richter and Palzkill [12] concluded that in friction welding of steel with graphite-containing cast iron, the influence of graphite in ductile iron on the welding process must also be taken into account, because this graphite builds up a lubrication layer which impedes the generation of an intensive frictional force and, consequently, the development of heat. Dette and Hirsch [13] joined steel and ductile iron with friction welding. The authors mentioned the main advantage to applying of ductile iron was the weight saving of the part following the $10 \%$ lower gravity of ductile iron than standard steel. The aim of next welding trials was to obtain a high mechanical tensile strength of joining during the exploitation of a given element. Michiura et al. [14] demonstrated the application of friction welding for ductile cast iron pipes. The authors concluded that the tensile strength decreased with increasing layers of deformed spheroidal graphite. Shinoda et al. [15], from Nagoya University in Japan, stated that ductile iron can be joined by friction welding without any special treatment, such as preheating and/or post-heating treatment. Ochi et al. [16] tested the macrostructure and temperature distribution near the interface during the friction welding of FC250 grade cast iron. Their highest reported tensile strength in solid joints and pipe joints were, respectively, 317 and $381 \mathrm{MPa}$. Song et al. [17] examined the strength distribution at the interface of rotary friction-welded aluminium to ductile iron. The results of the investigations concerning the microstructure and mechanical properties of friction-welded ductile iron with stainless steel and Armco iron were provided in the papers $[18,19]$.

A review of the literature shows that in order to produce a good quality joint for welding of ductile iron, many solutions are used. These include the introduction of the low carbon steel interlayers and changing the geometric shape of the joined parts, which are also heat treated before and/or after the friction welding process. Regardless of the type of material, these technologies complicate the welding process, increase its duration and make the technology more expensive. According to the ASM [20], the friction welding process parameters play a significant role in making good quality joints. Rotational or tangential speed, pressure at the weld interface and heating time are the variables that must be considered in direct drive friction welding. Thus, identifying the suitable combinations of the process input parameters to produce the desired output requires many experiments, making this process time consuming and costly [21]. In order to overcome this problem, various optimisation methods can be applied to define the desired output variables through developing mathematical models to specify the relationship between the input parameters and output variables. In the last two decades, design of experiment (DOE) techniques have been used to carry out such optimisation [22].

As it is mentioned above, the available knowledge on friction welding of ductile iron is focused on the structural and mechanical properties, phase transformation and tensile strength evolution. All these investigations were carried out through trial and error method to attain optimum welding conditions. The combined effects of process parameters on tensile strength in DI with LCS friction-welded joints are hitherto not reported. Only other materials such as stainless steel, aluminium alloys, magnesium or titanium alloys were considered by many researchers. The main factor responsible for this situation may be the fact that ductile iron is generally considered to be the material difficult to weld.

Therefore, the first aim of this paper is to employ response surface methodology to develop empirical relationships concerning friction welding input parameters: friction force, friction time and upset force and output response: tensile strength for the LCS-DI joints. The second aim is to find the optimal parameter welding combination that would maximise the ultimate tensile strength of friction welding joints. Moreover, we would like to take a closer look into metallurgical phenomena, accompanying the friction welding of ductile iron with steel.

\section{Experimental details}

\subsection{Material selection}

The friction welding was done on ductile iron (ASTM A 536) with low carbon steel (AISI 1020) rods sized $20 \mathrm{~mm}$ in diameters and $100 \mathrm{~mm}$ in length. The chemical composition of the base materials is presented in Table 1. The mechanical properties of the base materials are presented in Table 2. The microstructure of the as-cast DI showed a bull's eye structure with ferrite surrounding the graphite nodules in a pearlitic matrix (Fig. 1a). The microstructure of LCS steel showed a matrix of ferrite grains and pearlite (Fig 1b).

\subsection{Friction welding setup}

The process of joining was carried out on the continuous drive friction machine type of ZT-13. The surface for friction welding was prepared on the abrasive cutoff machine. The 
Table 1 Chemical composition of the base materials (wt\%)

\begin{tabular}{llllllllll}
\hline Material & $\mathrm{C}$ & $\mathrm{Si}$ & $\mathrm{Mn}$ & $\mathrm{P}$ & $\mathrm{S}$ & $\mathrm{Cr}$ & $\mathrm{Ni}$ & $\mathrm{Mg}$ & $\mathrm{Fe}$ \\
\hline Ductile iron & 3.55 & 2.40 & 0.30 & 0.06 & 0.007 & 0.003 & 0.05 & 0.03 & Balance \\
Low carbon steel & $0.18-0.23$ & $<0.05$ & $0.30-0.60$ & $<0.04$ & $<0.050$ & - & - & - \\
\hline
\end{tabular}

geometry of specimens used for friction welding and the basic steps in the friction welding process were presented in Fig. 2. As shown in Fig. 2, one workpiece is rotated and the other is held stationary. When the appropriate rotational speed is reached, the workpieces are brought together under axial force. Abrasion at the weld interface heats the workpiece locally and upsetting (axial shortening) starts. Finally, the rotation of the workpiece ceases and upset (forge) force is applied to consolidate the joint.

\subsection{Design of experiment}

The following independently controllable process parameters were identified to carry out the experiments: friction force $(F)$, friction time $(T)$ and upset force $(U)$. Other friction welding parameters like rotational speed and upset time could be set at any desired level within the range of the machine setting. Constant rotational speed $(1,450 \mathrm{rpm})$ and upset time $(3 \mathrm{~s})$ are used in this study. The working ranges of all of the selected parameters were fixed by conducting trial runs. This was carried out by one of the parameters varying whilst the rest of them was kept at constant values. The working range of each process welding parameter was decided upon by inspecting the weld for a smooth appearance without any visible defects. The upper and lower limits with different levels of the identified process parameters are presented in Table 3. The selected design matrix (see Table 4) is a central composite face-centred factorial design consisting of 20 sets of coded conditions [22]. It comprises a full replication of $2^{3}(8)$ factorial design plus six centre points and six star points. All friction welding variables at the intermediate level $(0)$ constitute the centre points and the combinations of each of the welding variables at either their lowest $(-1)$ level or highest $(+1)$ level with the other two variables at the intermediate levels constituting the star points. Thus, the 20 experimental runs allowed for the estimation of the quadratic and twoway interactive effects of the friction welding parameters.

\subsection{Methods}

As prescribed by design matrix (Table 4), 20 joints were fabricated. The tensile specimens comprising the welded joints were machined to the required dimensions according to the ASTM E8M-04 standard [23]. Three tensile specimens were prepared for different welding conditions to predict the transverse tensile strength. The tensile strength test was carried out on a $100-\mathrm{kN}$ servo-controlled universal testing machine (Instron). From each joint, the average of three results was presented in Table 4.

Vickers hardness testing machine was employed for measuring the hardness of the friction-welded specimens for the optimised conditions. The hardness of the joints across the interface was measured with $0.5 \mathrm{~kg}$ load at $15 \mathrm{~s}$ dwell time.

The microstructure analysis of the optimised joints was carried out on the optical microscope (OM). The specimens were mechanically polished by using emery special sheets with the help of disc and bench polishing machine. The prepared specimens were etched by applying $2 \%$ nital for inspecting the metallurgical behaviour of the welded joints. Moreover, the electron microscopy was performed on a JEOL JSM-5400 scanning electron microscope (SEM) equipped with a LINK ISIS 200 energy-dispersive X-ray spectrometer. The surfaces of specimens were observed in BEI COMPO microscope mode using back-scattered electrons (BSE). Additionally, the studies were conducted on the interface using energy-dispersive spectroscopy (EDS) linear and the map analysis. The aim of the EDS linear analysis was to determine the changes in the distribution of carbon across the interface.

\section{Results and discussion}

\subsection{Developing empirical relationships}

The relationship between ultimate tensile strength (UTS) of the friction-welded LCS-DI joint is a function of the friction welding parameters such as a friction force $(F)$,

Table 2 Mechanical properties of the base materials

\begin{tabular}{lllll}
\hline Material & Tensile strength (MPa) & Yield strength (MPa) & Elongation (\%) & Hardness (HV) \\
\hline Ductile iron & 552 & 379 & 6 & 250 \\
Low carbon steel & 395 & 295 & 36 & 115 \\
\hline
\end{tabular}


Fig. 1 Optical microstructure of parent metals. a Micrograph of the as-cast ductile iron showing a bull's eye structure with ferrite surrounding the graphite nodules in a pearlitic matrix. $\mathbf{b}$

Micrograph of low carbon steel showing a matrix of ferrite grains and pearlite. Etched by $2 \%$ nital
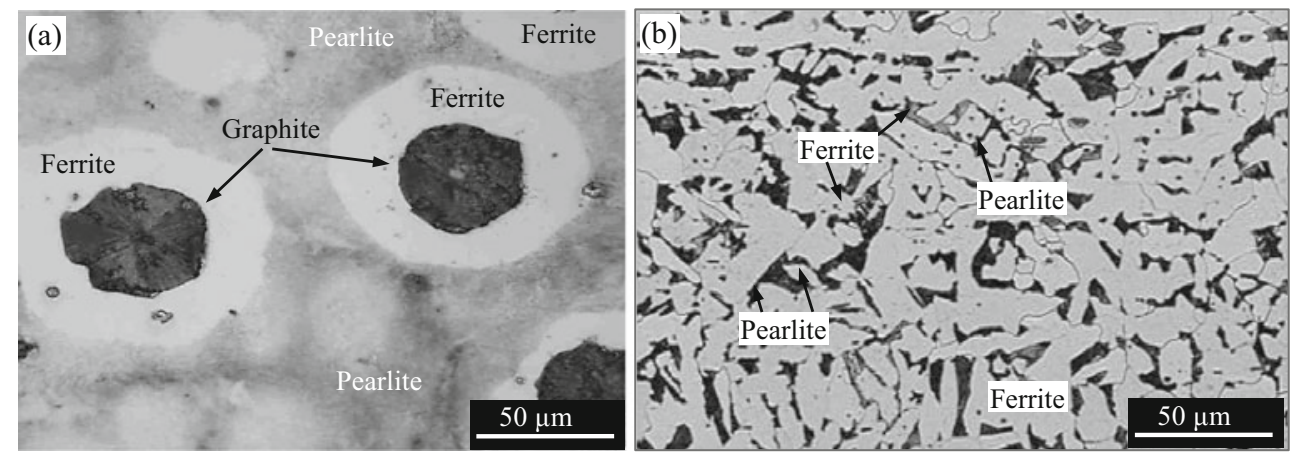

friction time $(T)$ and upset force $(U)$, which can be expressed as:

$Y(\mathrm{UTS})=f(F, T, U)$

The mathematical model to establish the relationships between input and output parameters was developed using Design-Expert Software (DES) [24] at a confidence level of $95 \%$. The tensile strength was expressed as a non-linear function of process parameters.

The second-order polynomial equation that represents the response surface $Y$ is:

$Y=b_{0}+\sum b_{i} x_{i}+\sum b_{i i} x_{i}^{2}+\sum b_{i i} x_{i} x_{j}$

When considering three parameters, the selected polynomial could be expressed as:

$$
\begin{aligned}
Y= & b_{0}+b_{1}(F)+b_{2}(T)+b_{3}(U)+b_{12}(F T)+b_{13}(F U)+b_{23}(T U) \\
& +b_{11}\left(F^{2}\right)+b_{22}\left(T^{2}\right)+b_{33}\left(U^{2}\right)
\end{aligned}
$$

where $b_{0}$ is the average of responses and $b_{i}$ and $b_{i j}$ are the response coefficients that depend on a response coefficient that depend on respective main and interaction effects of the parameters.

A central composite design which accurately fits the secondorder response surface was used in this work. The value of the coefficient was calculated by applying central composite design using DES. The significance of each of the model terms was checked using $p$ values. A value of $p$ less than 0.05 indicates that the model terms are significant. The values greater than 0.05 indicate that the model terms are not significant. Values greater than 0.1 indicate the model terms are not significant. Insignificant model terms that are not satisfying the above said criteria have been eliminated by the backward elimination regression method, without affecting much of the accuracy of the model [24]. The final mathematical relationships between welding variables to predict tensile strength of friction welding joints, developed by the statistical design of experiments procedure, are given below.

Final equation in terms of coded factors is as follows:

$$
\begin{aligned}
\mathrm{UTS} & =288.37+14.30(F)+19.30(T)-11.20(U) \\
& +12.13(F T)-7.12(F U)-51.12(T U)+2.82\left(F^{2}\right) \\
& +65.82\left(T^{2}\right)+9.32\left(U^{2}\right)
\end{aligned}
$$

The final equation in terms of actual factors is as follows:

$$
\begin{aligned}
& \mathrm{U} \mathrm{T} \mathrm{S}=419.98-13.749(F)-8.504(T)+9.908(U) \\
& \quad+0.242(F T)-0.204(T U)+0.704\left(F^{2}\right)+0.105\left(T^{2}\right)+0.093\left(U^{2}\right)
\end{aligned}
$$

The adequacy of the developed relationship was tested using the analysis of variance technique (ANOVA). In this research, the desired level of confidence was considered to be $95 \%$. The basic adequate ANOVA test results for all responses are presented in Table. 5. The model $F$ value of 44.11
Fig. 2 Experimental setup for continuous drive friction welding with the basic steps in the welding process
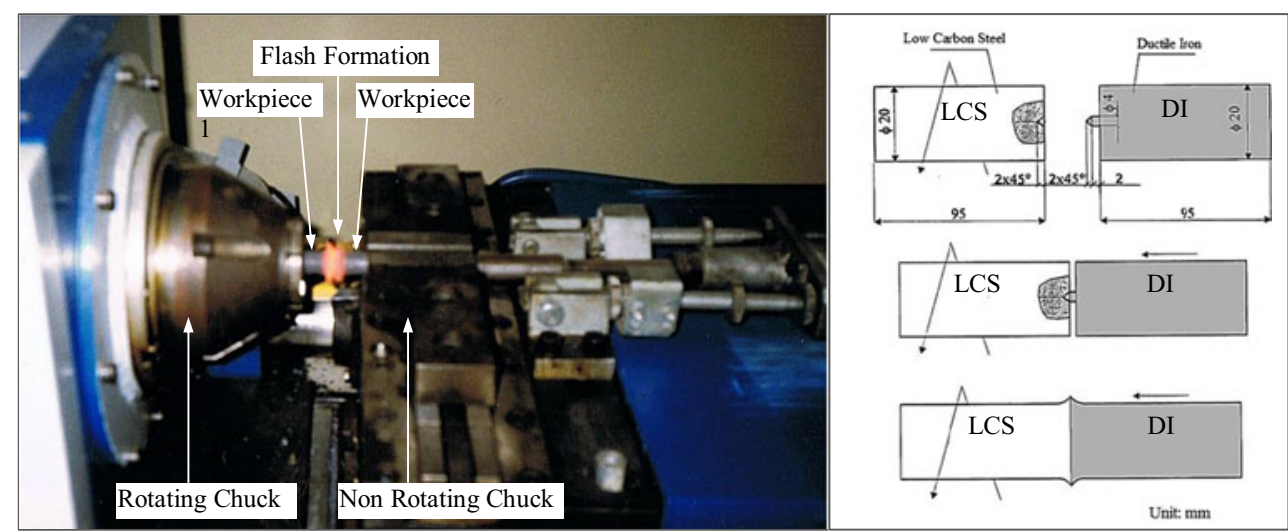
Table 3 Process variables and their bounds

\begin{tabular}{llllll}
\hline Parameter & Notation & Unit & \multicolumn{3}{l}{ Factor levels } \\
\cline { 4 - 6 } & & & -1 & 0 & 1 \\
\hline Friction force & $F$ & $\mathrm{kN}$ & 11 & 13 & 15 \\
Friction time & $T$ & $\mathrm{~s}$ & 40 & 65 & 90 \\
Upset force & $U$ & $\mathrm{kN}$ & 27 & 37 & 47 \\
\hline
\end{tabular}

for tensile strength implies the model is significant. The coefficient of determination $R^{2}$ is used to find how close the predicted and experimental values lie. The value of $R^{2}$ for tensile strength indicates that a high correlation exists between the experimental and predicted values exists. The 'adequate precision' measures the signal-to-noise ratio. A ratio greater that 4 is desirable. There is an adequate signal in all models. Each predicted value matches well its experimental value, as shown in the correlation graph in Fig. 3.

\subsection{Optimisation of welding parameters}

To predict the welding parameters accurately without consuming time, materials and labour effort, in recent years, various methods have been available with genetic algorithms (GAs) amongst others. GAs were applied into the wide range of

Table 4 Design matrix and experimental design

\begin{tabular}{|c|c|c|c|c|c|c|c|}
\hline \multirow[t]{2}{*}{ Trial no. } & \multicolumn{3}{|c|}{ Coded value } & \multicolumn{3}{|c|}{ Actual value } & \multirow{2}{*}{$\begin{array}{l}\text { Responses } \\
\text { UTS }\end{array}$} \\
\hline & $F$ & $T$ & $U$ & $F$ & $T$ & $U$ & \\
\hline 1 & -1 & -1 & -1 & 11 & 40 & 27 & 304 \\
\hline 2 & 1 & -1 & -1 & 15 & 40 & 27 & 315 \\
\hline 3 & -1 & 1 & -1 & 11 & 90 & 27 & 414 \\
\hline 4 & 1 & 1 & -1 & 15 & 90 & 27 & 496 \\
\hline 5 & -1 & -1 & 1 & 11 & 40 & 47 & 378 \\
\hline 6 & 1 & -1 & 1 & 15 & 40 & 47 & 383 \\
\hline 7 & -1 & 1 & 1 & 11 & 90 & 47 & 306 \\
\hline 8 & 1 & 1 & 1 & 15 & 90 & 47 & 337 \\
\hline 9 & -1 & 0 & 0 & 11 & 65 & 37 & 283 \\
\hline 10 & 1 & 0 & 0 & 15 & 65 & 37 & 297 \\
\hline 11 & 0 & -1 & 0 & 13 & 40 & 37 & 343 \\
\hline 12 & 0 & 1 & 0 & 13 & 90 & 37 & 363 \\
\hline 13 & 0 & 0 & -1 & 13 & 65 & 27 & 290 \\
\hline 14 & 0 & 0 & 1 & 13 & 65 & 47 & 303 \\
\hline 15 & 0 & 0 & 0 & 13 & 65 & 37 & 289 \\
\hline 16 & 0 & 0 & 0 & 13 & 65 & 37 & 290 \\
\hline 17 & 0 & 0 & 0 & 13 & 65 & 37 & 291 \\
\hline 18 & 0 & 0 & 0 & 13 & 65 & 37 & 287 \\
\hline 19 & 0 & 0 & 0 & 13 & 65 & 37 & 286 \\
\hline 20 & 0 & 0 & 0 & 13 & 65 & 37 & 292 \\
\hline
\end{tabular}

Table 5 ANOVA results for ultimate tensile strength

\begin{tabular}{lll}
\hline & $F$ value & Prob $>F$ \\
\hline Model & 44.11 & $<0.0001$ \\
$F$ & 14.34 & 0.0036 \\
$T$ & 26.13 & 0.0005 \\
$U$ & 8.80 & 0.0141 \\
$F \cdot T$ & 8.25 & 0.0166 \\
$F \cdot U$ & 2.85 & 0.1223 \\
$T \cdot U$ & 146.67 & $<0.0001$ \\
$F^{2}$ & 0.15 & 0.7037 \\
$T^{2}$ & 83.56 & $<0.0001$ \\
$U^{2}$ & 1.67 & 0.2247 \\
Model statistics & Tensile strength & \\
Coefficient $R^{2}$ & 0.97 & \\
Adjusted $R^{2}$ & 0.95 & \\
Predicted $R^{2}$ & 0.74 & \\
Adequate precision & 24.23 & \\
\hline
\end{tabular}

engineering problems including optimisation of process parameters in welding processes.

Murti et al. [25] developed a statistical experimental design model in friction welding dissimilar materials (low alloy steel to austenitic stainless steel, medium carbon steel to high speed steel and aluminium to stainless steel). Canyurt [26] developed the genetic algorithm welding strength model to estimate the mechanical properties of the welded joints for the brass materials. Paventhan et al. [27] used the RSM to optimise the friction welding parameters for joining aluminium alloy and stainless steel. Sathiya et al. [28] have conducted the optimisation of friction welding parameters using simulated annealing (SA), artificial neural networks (ANN) and evolutionary algorithms (EA). Kumaran et al. [29, 30] optimised a tube to tube plate using an external tool by genetic algorithms and Taguchi method. Dey et al. [31] conducted the optimisation of bead geometry in electron beam welding using a GA. A

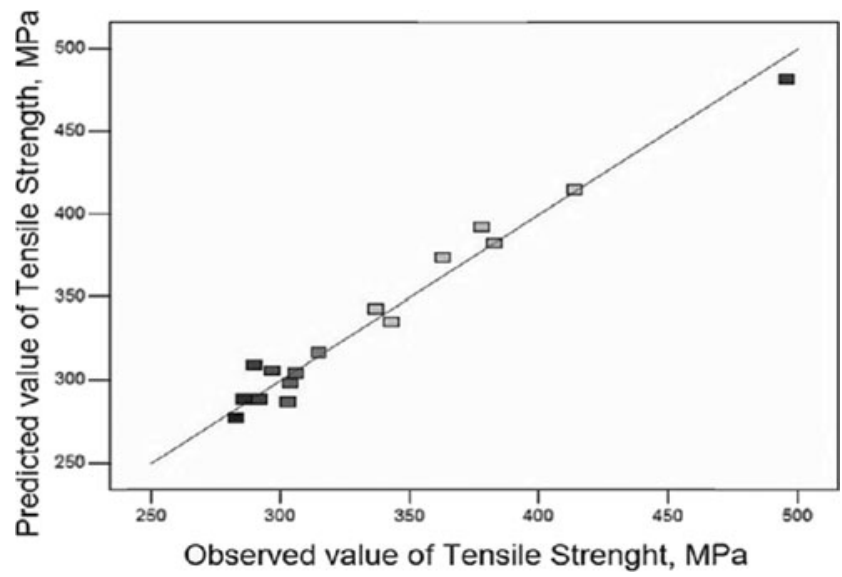

Fig. 3 Predicted value of tensile strength vs. observed value of tensile strength 
binary-coded genetic algorithm with a penalty term was used to solve the said problem. Prediction of tensile strength and optimisation of process parameters for friction stir-welded dissimilar aluminium alloys [32, 33] and stainless steel [34] were also conducted in the papers. Elangovan et al. [35] studied a parametric optimisation of ultrasonic metal welding using RSM and GA approach. A hybrid intelligent method for evaluating the near optimal settings of the friction welding process parameters of ductile iron was conducted by Winiczenko et al. [36]. The optimisation of welding parameters was carried out in an automatic cycle with the use of support vector regression (SVR), GA and imperialist competitive algorithm (ICA). Udayakumar et al. [37] carried out an experimental investigation and multi-objective genetic algorithm (MOGA) optimisation of friction welding parameters for super duplex stainless steel joints.

GAs are a search method based on natural selection and heredity mechanisms. It is very universal, with simple procedures regulating the search for the best solutions and using the stochastic method. GAs use the evolutionary principle of survival characteristic for the most adapted individuals [38, 39]. The general optimisation procedure using a genetic algorithm is shown in Fig. 4.

These algorithms encode a potential solution to a specific problem on a simple chromosome string and apply specified operators to a chromosome so as to preserve critical information and to produce a new set of population with the purpose of generating strings which map to high function values [40].

The basic genetic algorithm (Fig. 4), also called the elementary or simple genetic algorithm, contains the following steps:

Step 1 Generating randomly generate an initial chromosome population

Step 2 Decoding the genes, namely $F, T$ and $U$ of all chromosomes

Step 3 Evaluating the predicted value of weld strength using the RSM model. Determine the maximum fitness of all chromosomes in the population

Step 4 Checking the stopping criterion

Fig. 4 The general structure of the genetic algorithms

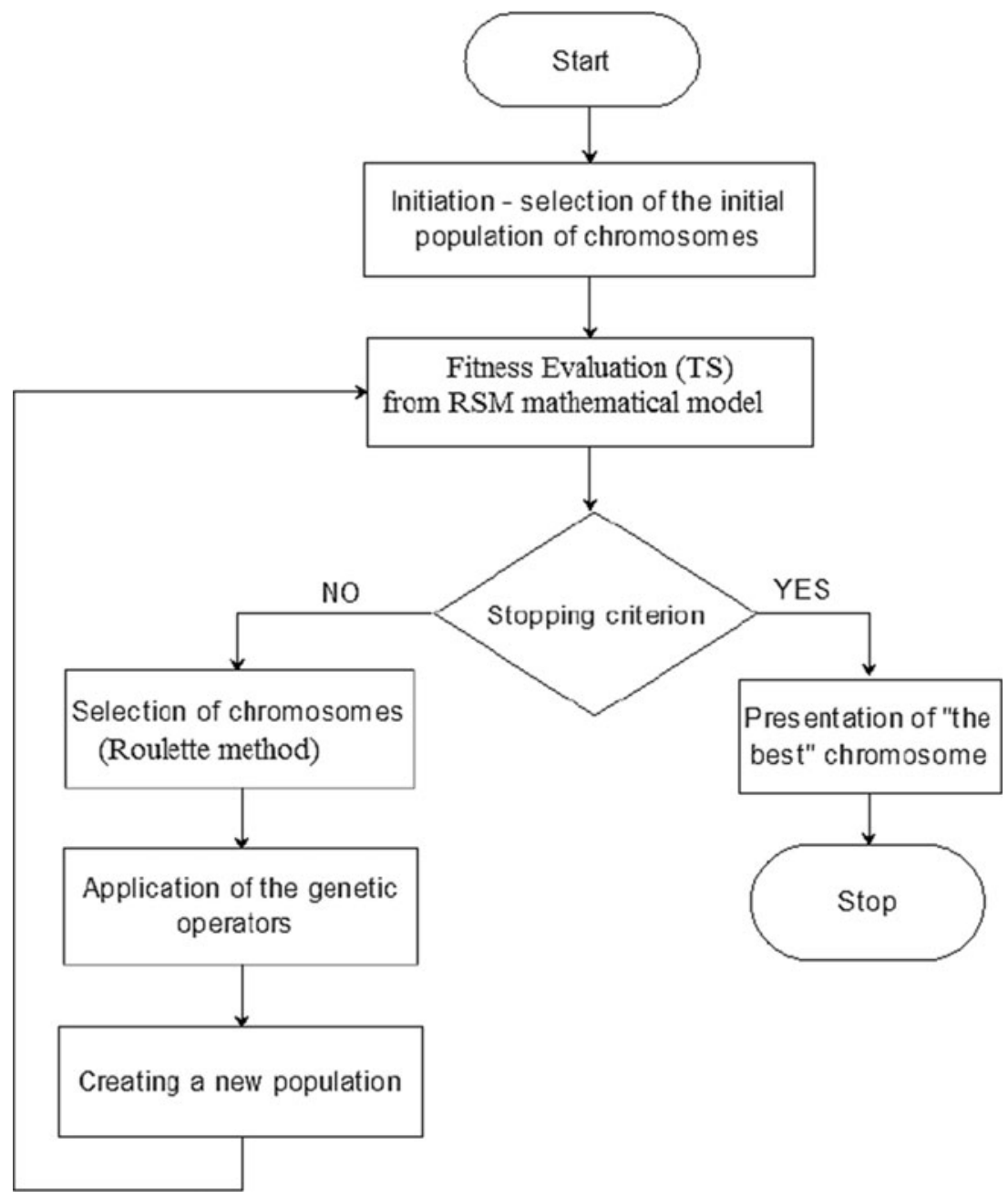


Step 5 Selection of chromosomes

Step 6 Using genetic operators

Step 7 Creating a new population

Step 8 Presentation of the 'best' chromosome

A Matlab function was written using the developed RSM model in terms of actual factors (see Eq. 5). This function was called the fitness function for the optimisation problem. Therefore, the fitness function was a function maximising the tensile strength of welding joints. Experimental ranges were placed as bounds on the three input variables which are shown below:

- Constraints on friction force

$11 \leq F \leq 15$

- Constraints on friction time

$40 \leq T \leq 90$

- Constraints on upset force

$27 \leq U \leq 47$

The genetic algorithm options are shown in Table 6. The optimised achievement after 120 iterations is shown in Fig. 5. The weighted average change in the fitness function value over of 150 generations was used as the criteria for stopping the GA algorithm.

The best input parameters obtained throughout GA were used to process the friction joints experimentally.

\subsection{Effect of welding process parameters on tensile strength}

The direct effect of the process parameters on the UTS responses has been found from the developed mathematical model. The variation of the responses with respect to each of the three process parameters, friction force, friction time and

Table 6 The genetic algorithm settings

\begin{tabular}{ll}
\hline Population size & 20 \\
\hline Selection function & Roulette \\
Crossover friction & 0.8 \\
Crossover function & Single point \\
Migration function & Forward \\
Number generations & 200 \\
Stall generations & 150 \\
\hline
\end{tabular}

upset force, were plotted by keeping two parameters constant at their central level and varying the third within the upper and lower bounds. The individual variations of the responses with actual welding parameters are presented in Fig. 6.

Figure 6 a shows the effect of friction force on tensile strength of the welds. From Fig. 6a, it can be observed that tensile strength increases with an increase in friction force. The same phenomenon has been reported during friction welding of mild steel. According to Ellis [41], as the friction welding pressure increases, within limits, the tensile strength of the weld increases, approaching parent metal.

Upset force has a negative effect on tensile strength. As upset force increases, the tensile strength decreases. Figure $6 \mathrm{~b}$ shows the effect of upset force on the ultimate tensile joint. Similar results were also reported by Kurt et al. [42]. They believed that the tensile strength decreases slightly with increasing the upset force. This effect is probably due to the easy deformation of soft material at high forging pressure, as reported by Ates et al. [43].

According to the ASM [20], due to the high heat produced under increased friction force, friction weld may behave like hot worked material. The weld metal area has been reduced when the hot forged conditions are increased. It could enhance the more austenite phase in the weld zone. Therefore, the tensile strength found to be decreasing as upset force steps up, reaches a minimum and then increases. With high upset force (Fig. 6b), tensile strength started increasing mainly due to the strain induced deformation as reported by Udayakumar et al. [37].

Friction force and friction time have a positive effect on tensile strength. As friction force and friction time increase, the tensile strength also increases. However, initially, the tensile strength decreases as friction time increases from 40 to $60 \mathrm{~s}$, reaches a minimum and then increases (see Fig. 6c). The same phenomenon has been reported during friction welding of dissimilar materials by Sahin [44, 45].

The interaction effects of the process parameters on UTS have been found from a developed mathematical model, which are shown in Fig. 7.

Figure $7 \mathrm{a}$ shows the interaction effects of friction force and friction time on tensile strength. It is evident that the decreasing trend of tensile strength flattens as friction time changes from 40 to $50 \mathrm{~s}$. As friction time proceeds, the tensile strength shows an increasing trend as friction force increases. It can be observed that there is a sudden increase in tensile strength as friction time changes from 60 to $90 \mathrm{~s}$.

Figure $7 \mathrm{~b}$ shows the interaction between the upset force and friction force on tensile strength. It is clear that the curves show the same trend as the upset force increases. Tensile strength slowly decreases as friction force decreases. 
Fig. 5 The results of genetic algorithm optimisation. a Converged values of welding parameters. b Convergence of fitness values

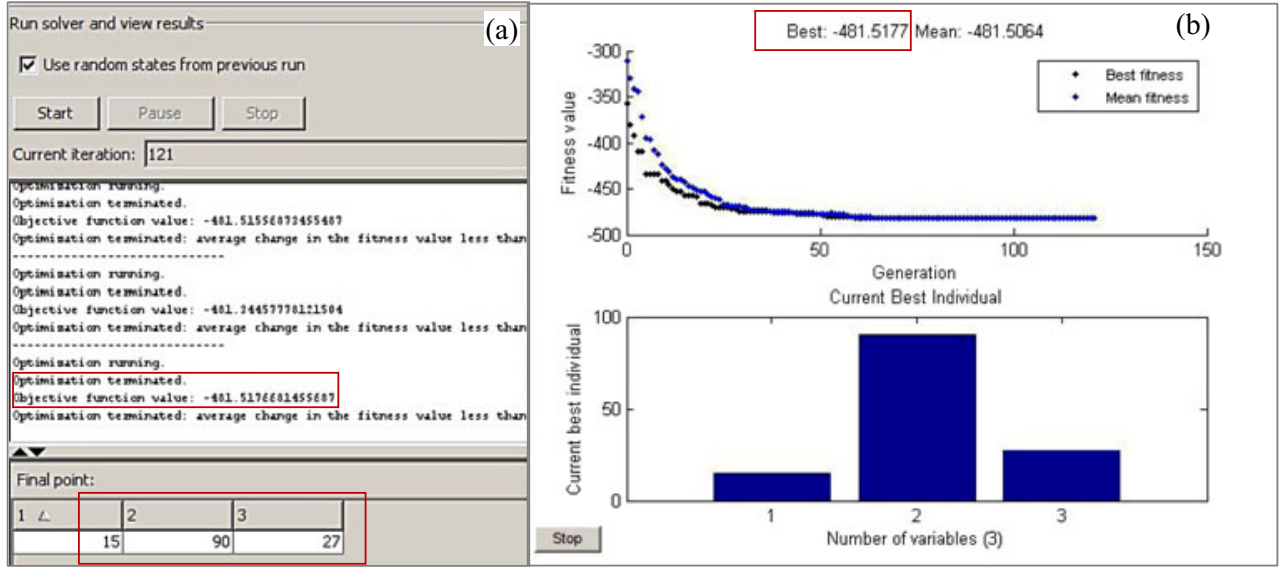

\subsection{Validation of experiment}

A predicted maximum tensile strength of the friction-welded specimen which is $482 \mathrm{MPa}$ could be attained under the welding conditions of friction force of $15 \mathrm{kN}$, upset force of $27 \mathrm{kN}$ and friction time of $90 \mathrm{~s}$. The experimentally determined tensile strength was found to be $480 \mathrm{MPa}$ and could be attained under the welding conditions of friction force of $15 \mathrm{kN}$, upset force of $27 \mathrm{kN}$ and friction time of $90 \mathrm{~s}$ which show the consistency of the model.

Three further validation experiments were performed and the response of both models was found in agreement with the experimental results. The results of the confirmation experiments are shown in Table 7. To test the accuracy of a developed model in practical applications, conformity test runs were conducted by assigning different values for the process parameter within their working ranges but are different from that of the design matrix. These tests were conducted using the same experimental setup to demonstrate the reliability of the predicted values. The conformity tests show the accuracy of a developed model which is above $95 \%$. A maximum error obtained in the validation process was $2.35 \%$.

\subsection{The Vickers hardness measurements}

The variations of hardness the welded specimens for different welding parameters are shown in Fig. 8. The measurements were carried out along the central axis for LCS-DI joints.

As could be expected, the hardness reaches its maximum close to the interface and decreases very rapidly in the LCS region (Fig. 8). Contrary to this, the hardness decrease in DI is much slower and exhibits some kind of plateau. As can be
Fig. 6 Effect of the process parameters on tensile strength. a Friction force on tensile strength. b Upset force on tensile strength. c Friction time on tensile strength (a)
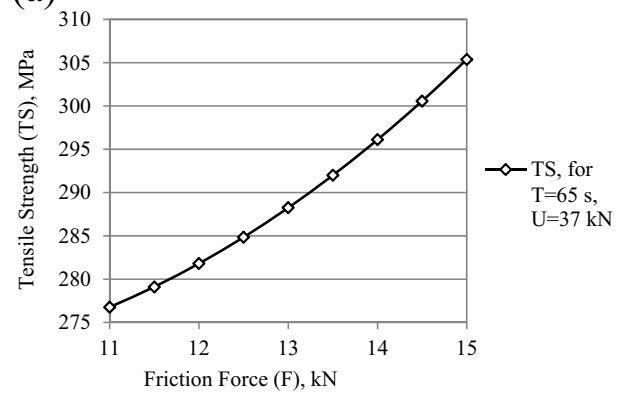

(c)

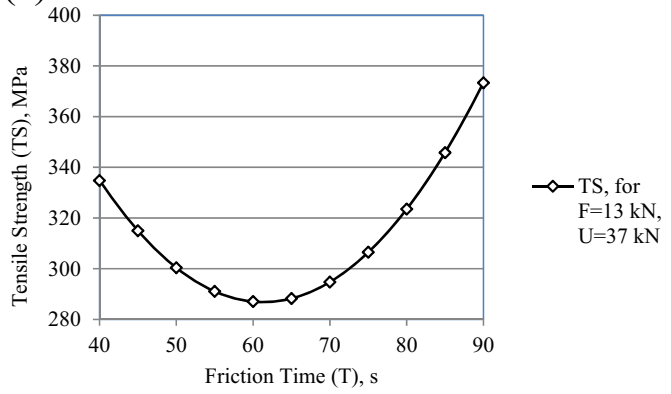

(b)

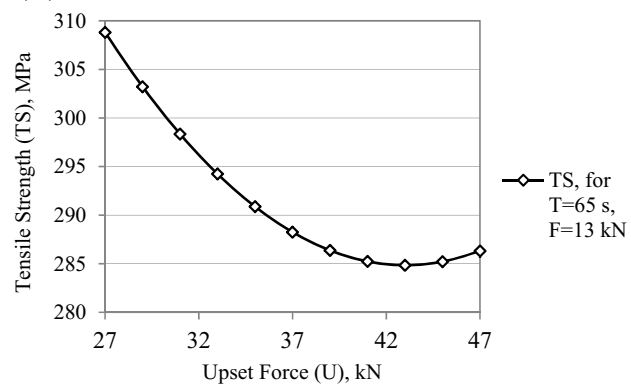


(a)

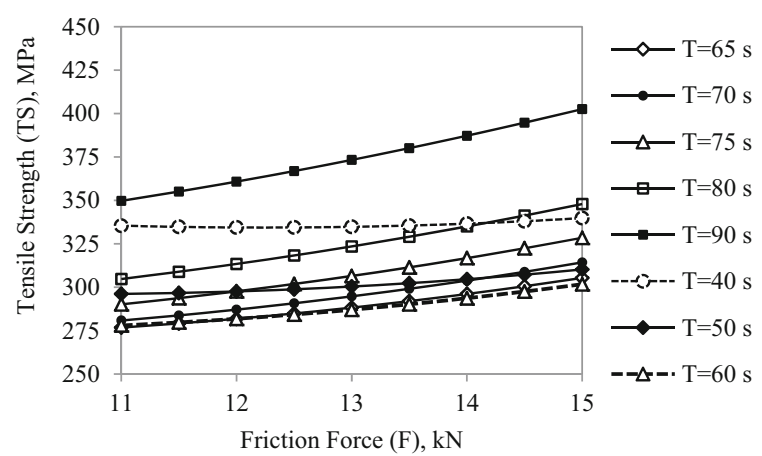

(b)

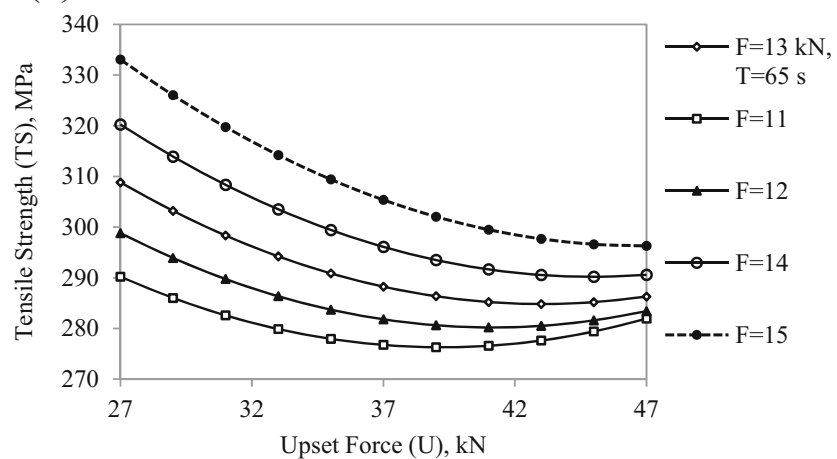

Fig. 7 Interaction effect of the process parameters on tensile strength. a Friction force and friction time on tensile strength. b Upset force and friction force on tensile strength

observed from the diagram, this plateau extends to 1.2 or $8 \mathrm{~mm}$ from the interface, depending on the location of the hardness measurements and reaches the value that is typical of the parent material. The hardness values generally increased with increasing friction pressure and upset pressures, but hardness values decreased with increasing upset time [42].

The maximum hardness value obtained in close proximity to the interface reached $552 \mathrm{HV}$ for no optimised DI joint. Compared to the microstructure shown in Fig. 11, this increase can be explained by the formation of martensite at the weld joint. It was thought that this structure was generated because the material was intensively heated and rapidly cooled during the friction welding process. The formation of martensite reduces the mechanical properties of friction weldment. However, the microstructure may be controlled by the welding parameters [46]. In order to minimise martensite

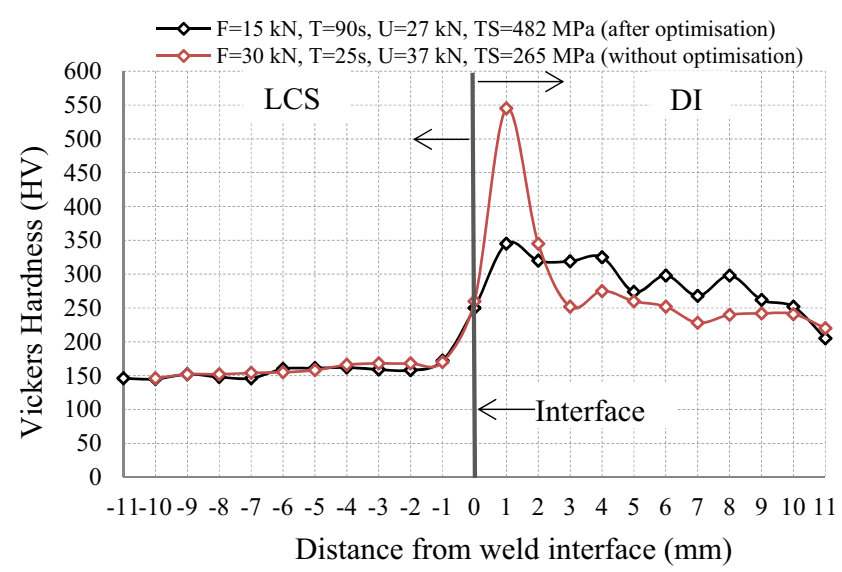

Fig. 8 The Vickers hardness distributions of low carbon steel-ductile iron friction-welded joint at various welding parameters

formation, the peak temperature was decreased below the eutectoid temperature [47]. This decrease in temperature prevented any transformation and decreased the cooling rate of the weldment. Therefore, it is possible to obtain a full recrystallized ferritic structure if the welding conditions are controlled properly to avoid an austenite phase transformation [46]. In the long-time welding, the heating time was prolonged to increase the maximum temperature at the weld interface, to increase the time for axial conduction of heat into the two work pieces and to decrease the subsequent cooling rate [48].

After optimisation of welding parameters, the maximum hardness value for DI decreased to $\sim 350 \mathrm{HV}$ for DI when the distance to the centre of the weld was $1.2 \mathrm{~mm}$. Similar values of the hardness distribution between ductile iron and low alloy steel joints have been noticed in the literature [11].

The result shows the hardness of the welded specimen decreases more rapidly when the phase changes from fully deformed zone to heat-affected zone for both welded joints.

The changes of the hardness in the welding interface are directly associated with the microstructure resulted from the degree of the heat being introduced and plastic deformation $[42,49]$. After optimisation, the hardness of the weld interface has increased only to $71 \%$ for DI and $44 \%$ for LCS of the base metals, respectively. This is a very small variation comparing with the other fusion welding process. The results of microstructures of friction welds as a function from the interface are described below.

Table 7 Validation test results

\begin{tabular}{|c|c|c|c|c|c|c|}
\hline \multirow{2}{*}{$\begin{array}{l}\text { Test run } \\
\text { No. }\end{array}$} & \multicolumn{3}{|c|}{ Process parameters } & \multirow{2}{*}{$\begin{array}{l}\text { Experimental value } \\
\text { UTS (MPa) }\end{array}$} & \multirow{2}{*}{$\begin{array}{l}\text { Predicted value } \\
\text { UTS (MPa) }\end{array}$} & \multirow{2}{*}{$\begin{array}{l}\% \text { of error } \\
\text { UTS }\end{array}$} \\
\hline & $\mathrm{F}$ & $\mathrm{T}$ & $U$ & & & \\
\hline 1 & 14 & 70 & 40 & 290 & 297 & -2.35 \\
\hline 2 & 15 & 85 & 25 & 465 & 457 & 1.75 \\
\hline 3 & 12 & 80 & 30 & 337 & 345 & -2.31 \\
\hline
\end{tabular}

$\%$ of error $=[($ experimental value - predicted value $) /$ predicted value $] \times 100$ 
Fig. 9 Microstructure section of the low carbon steel-ductile iron joint at the interface. a Microstructure of LCS/DI joint at the weld interface. $\mathbf{b}$

Microstructure of rotating sample. Etched by $2 \%$ nital
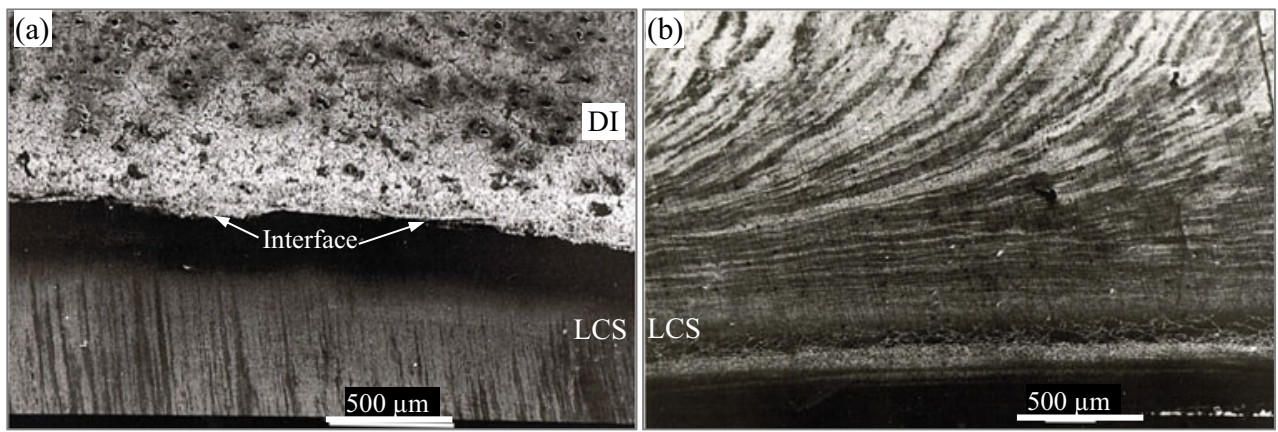

\subsection{Microstructure investigation}

The microstructural features of friction-welded LCS-DI dissimilar joint are shown in Fig. 9. The weld interface clearly shows the line of the joint. The microstructure of LCS-DI joint at the weld interface shows range and variety. The rotating LCS bar at the interface (Fig. 9b) exhibits a microstructure of a thin layer of highly deformed and refined grains. The grains are not uniform, and they have elongated due to the application of heat and pressure caused by thermomechanical action [11]. Because of the extensive mechanical deformation and heat produced during $\mathrm{FW}$, good welding only resulted when proper process parameters were used.

The results of the optical microstructure observations of the joints with selected welding parameters were given in Fig. 10. The microstructure observations were carried out in different areas of the HAZ in axis samples.

It was found that the ferrite structures in the original ductile iron had transformed into fine pearlite (P) and martensite (M) (Figs. 10a and 11) structures through rapid cooling from a high temperature state. Cheng et al. [46] indicated that the microstructure of high carbon steel by friction welding process mainly consisted of martensite when the peak temperature exceeds the $A_{1}$ (eutectoid temperature). On the other hand, when the welding was performed below $A_{1}$, no transformation occurred and no martensite formed [47].
Some ferrite grains also resulted from the friction welding process. Since the original ferrite structures were transformed into martensite, the FW processing temperature should be higher than the austenisation temperature of the material. Then, fine pearlite and martensite come into being during the cooling process. When the highest temperature in the ductile iron exceeds its eutectoid, the carbon in graphite will spread out to speed up the microstructure transformation into austenite by increasing the carbon concentration in the base metal. Whilst rapidly cooling, the austenite structure may transform into martensite [50].

In some areas of the micrograph, the carbide eutecticledeburite $(\mathrm{L})$ in the pearlitic matrix were identified. The appearance of ledeburite eutectic in DI can be explained only by the fact that the liquid-solid phase transformation had to proceed [43]. Considering the $\mathrm{Fe}-\mathrm{C}$ binary phase diagram (Fig. 12) [51], and due to high carbon content of the substrate ductile iron and high rate of solidification, it can be deduced that white hypoeutectic iron should form at the interface between the materials. Solidification in such irons begins by precipitation of an initial austenite phase which grows dendritically. When temperature falls off, more austenite will form and the carbon content of the remaining liquid simultaneously rises up to the eutectic composition. At the eutectic composition, the melt transforms into a mixture of austenite and cementite, called ledeburite $[52,53]$. The austenitic matrix
Fig. 10 Optical micrograph showing the microstructure of LCS-DI friction-welded joints at various welding parameters. a $F=$ $30 \mathrm{kN}, T=23 \mathrm{~s}$ and $U=37 \mathrm{kN}$. b $F=15 \mathrm{kN}, T=90 \mathrm{~s}$ and $U=27 \mathrm{kN}$ Etched by $2 \%$ nital
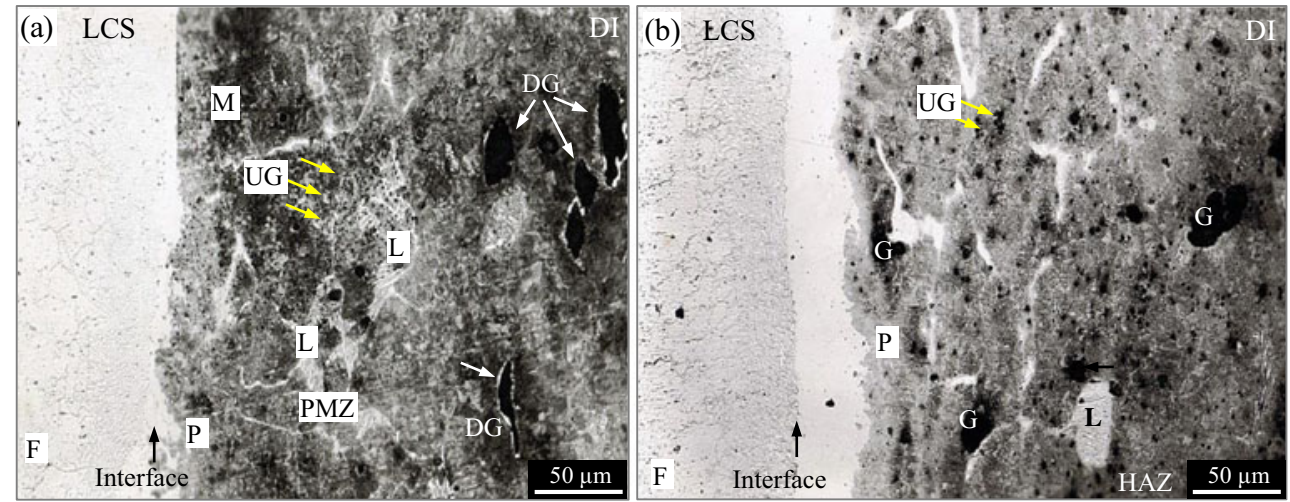


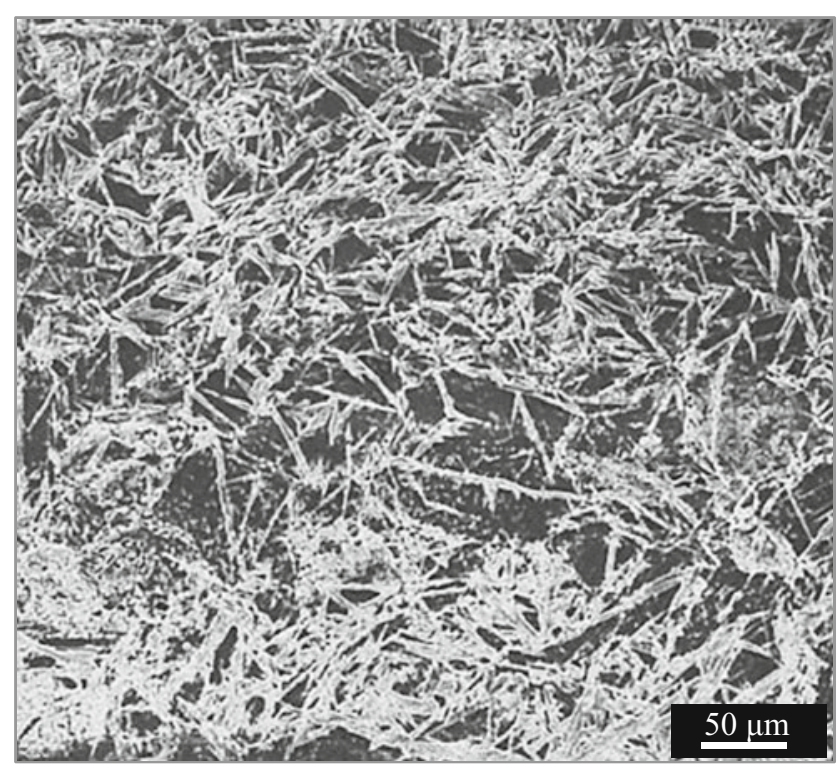

Fig. 11 Formation of martensite structure in DI at the weld interface. Etched by $2 \%$ nital

surrounding these carbides can also transform to martensite at lower temperatures [54].

The phase transformation sequences during the cooling of this partially melted zone (PMZ) can be summarised as:

$$
\begin{aligned}
\mathrm{L} & +\gamma+\mathrm{G}(\text { graphite }) \rightarrow \text { eutectic ledeburite }\left(\gamma+\mathrm{Fe}_{3} \mathrm{C}\right) \rightarrow \text { ledeburite } \\
& + \text { martensite }+\mathrm{G}
\end{aligned}
$$

The microstructure in different areas of the HAZ (Fig. 10a) also included the irregular and deformed graphite (DG) precipitates and microstructure of pearlite $(\mathrm{P})$ and ferrite $(\mathrm{F})$. The ferrite was mainly presented around the region of graphite nodules. Ultrafine graphite (UG) particles in white matrix were also detected. The graphite particles located adjacent to the bondline were ellipsoidal and oriented along the interface (Fig. 10a).

The microstructures changed significantly with using optimised parameters (Fig. 10b). The microstructure showed that the graphite nodules were only slightly deformed and retained globular morphology in comparison with that of the parent metal. At a friction welding time of $90 \mathrm{~s}$, the formation of pearlite structures was observed near the joining interface (Fig. 13a). This optimal condition removes martensite at the interface and improves the tensile properties of the weldments. In some areas of the micrograph, the carbide eutecticledeburite in the pearlitic matrix were also identified.

The most interesting transformation occurs in the decarburization zone of the DI specimens. The diffusion of carbon into steel favours the partial dissolution of graphite nodules during friction welding. According to Mitelea et al. [11], a higher friction time leads to higher temperature in DI, thus part of the carbon will be dissolved. The break-up of the spheroids has been observed and their renewed spheroidization to obtain less energetic morphologies (Fig. 10b). The formation process of this structure is similar to that observed by the authors [48].

The metallographic study showed that a diffusion of carbon occurs from the DI to the LCS. This diffusion causes the formation of a carbon-rich zone at the bond interface and a decarburization zone in the DI close to the bond interface (Fig. 13a). The carbon-rich zone in the LCS-DI joint has a typical ferritic-pearlitic microstructure with carbon contents that change gradually along with distance from the interface. Similar phenomenon was also observed by Mitelea et al. [11]
Fig. 12 Schematic Fe-C binary phase diagram of cast iron weld

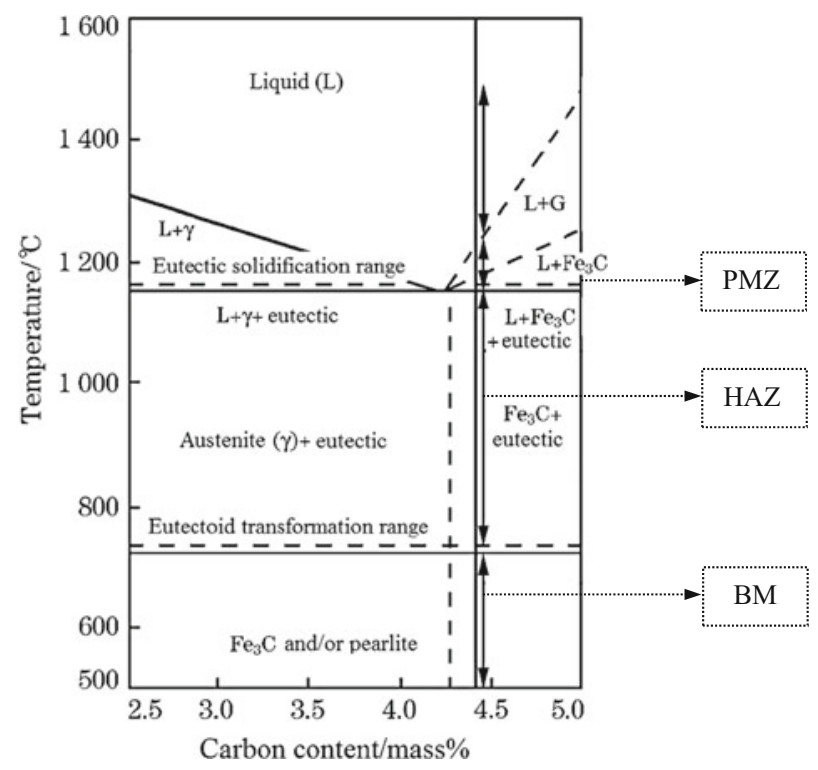

$$
C_{e q}=w_{C}+0.31 w_{S i}+0.33 w_{P}+0.45 w_{S}-0.028 w_{M n}+w_{M o}+w_{C r}-0.02 w_{N i}-0.01 w_{C u}
$$


Fig. 13 SEM micrographs showing the microstructure of LCS-DI joints closely to the interface. a Pearlite in the carburation zone. b Nodules precipitated in the rich carbon zone of the steel
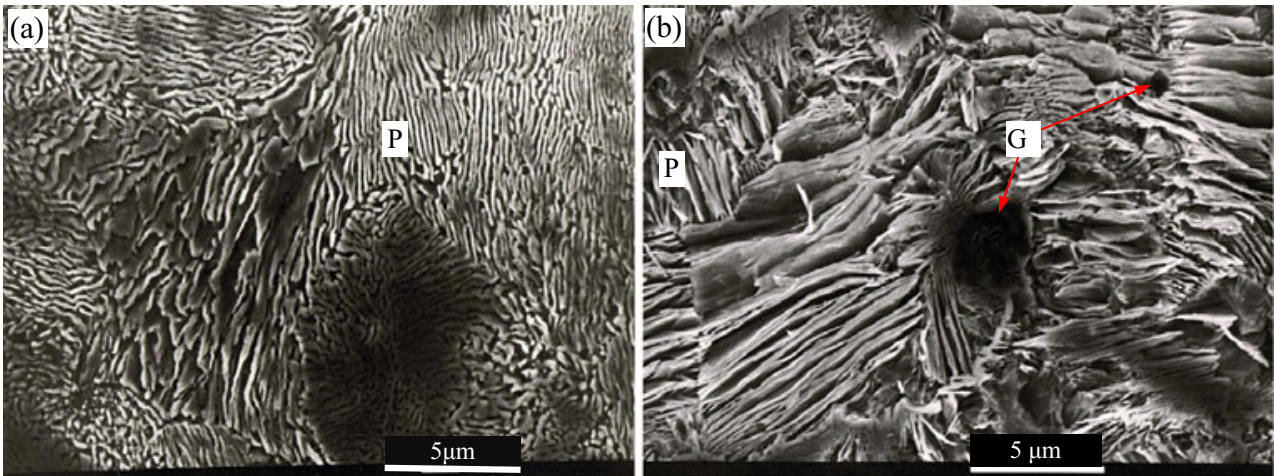

Carbon contents can be in excess of $0.8 \%$ near the interface; therefore, proeutectic cementite is formed at the grain boundaries in contact with the bond interface. The carbon content in the steel close to the interface can be higher that the solubility limit for carbon in austenite at the welding temperature. Therefore, when this occurs, the graphite nodule precipitation is observed (Fig. 13b) on the proeutectic cementite-austenite interfaces. The growth mechanisms of the graphite nodules are comparable with these proposed by Calvo et al. [55].

\subsection{Fractography}

The fracture surfaces of the tensile tested specimens were characterised using SEM to understand the failure patterns. The scanning electron micrograph of the fracture surface of the tensile specimen fabricated using optimum parameters is presented in Fig. 14. In the micrograph, the two different fracture morphologies have been distinguished in the LCS-DI samples. Microvoid coalescence (MCV) seems to be the dominant form of fracture in Fig. 14a. This type of fracture surface arises because microvoids are initiated at second phase particles during deformation. The dimple pattern around the graphite nodules show the deformation of the surrounding ferrite during the final period of straining up to fracture. Figure 14a also shows the relatively large cavity size in comparison with the graphite nodule size. Formation of cavity may be attributed to decohesion at the graphite and surrounding matrix.

The fracture surface of specimen in Fig. 14b showed mostly ductile dimples with a few cleavage facets. River markings on the facets result from the propagation of the crack on a number of planes of different levels. Cleavage fracture is a low energy, brittle fracture which propagates along low index crystallographic planes [56]. In addition, a microcrack formed at the graphite-matrix interface surrounded the nodule and then propagated to the matrix can be seen (arrows in Fig. 14b). Therefore, the fracture modes revealed plastic deformation around the graphite nodules and fracture mechanism are a mixture of cleavage and a dimple pattern reflecting the ductile nature of the heat-affected structure because of welding. A similar observation was also reported by Askari et al. [57].

\subsection{EDS-SEM investigation}

Energy-dispersive X-ray analysis (EDS) was carried out across the section of the friction-welded LCS-DI interface using optimum parameters. Figure 15 shows the results of the EDS linear analysis of carbon distribution across the interface of DI with LCS in the axis of the joined samples.

Analysis of the records clearly indicates a diffusion of carbon through the interface from DI to LCS. As a result of the
Fig. 14 SEM micrographs of the fracture surface for tensile test specimen. a Dimple mode of fracture; shallow dimples visible in the central part of the micrograph. b A mixture of cleavage and a dimple pattern mode
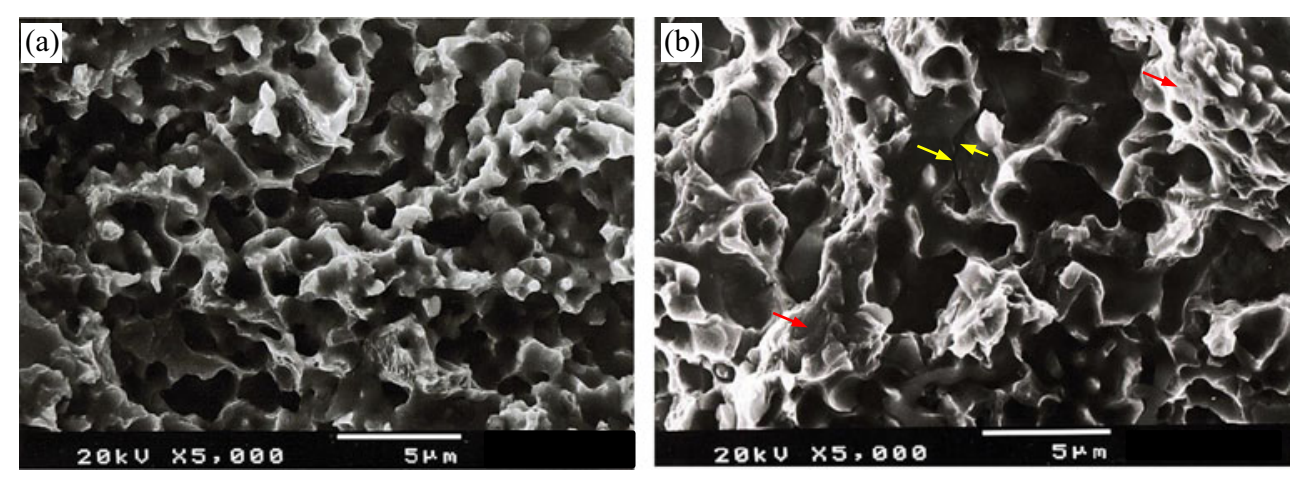

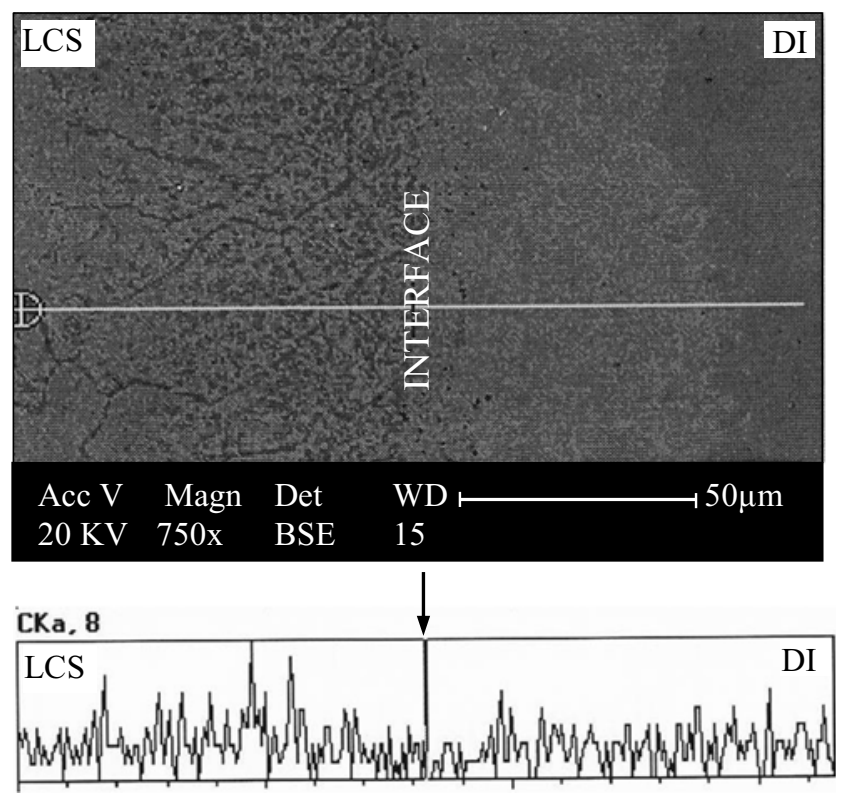

Fig. 15 EDS-line analysis of elements distribution across the interface of a LCS-DI joint

diffusion, a gradual reduction of carbon concentration in DI is observed whilst approaching the interface. The diffusion range of carbon equals $100 \mu \mathrm{m}$ in the axis of the steel samples. Details regarding the diffusion of carbon to various matrixes of DI have been described in a previous paper [19].
Figure 16 illustrates the results of the EDS map distribution of carbon and iron at the interface of the LCS-DI joints.

As can be seen in the maps, the matrix of DI (Fig. 16a, b), carbon occurs in the form of graphite clusters only, whilst in DI, carbon carbides also form and can be treated as 'more uniform'. During friction welding, the nodular graphite particles in the DI samples are deformed to give ellipsoids or are even flattened, at least in certain places. Therefore, the graphite acts as a lubricant and accordingly produces insufficient friction heat. This in turn means less heat in the friction interface zone, thus a lower temperature and lower diffusion coefficient. As such, the properties of the mechanical joints at the interface are reduced significantly. This phenomenon was earlier reported by many authors $[11,12,18]$.

The microstructure observation with using optimised parameters (Fig. 16c, d) showed that nodular graphite was slightly deformed only and retained a globular morphology in comparison with that of the parent material. These observations are consistent with the results of the EDS linear microanalysis and confirm the results of hardness changes at the interface. The results clearly showed that the friction welding process is inherent to the process of carbon transport through the DI-LCS steel interface. As a result of this process, there is an enrichment of steel with carbon atoms and it forms a solid solution with iron.
Fig. 16 EDS maps illustrating the carbon and iron distribution in the interface of a LCS-DI joint at various welding parameters. $\mathbf{a}, \mathbf{b}$ $F=30 \mathrm{kN}, T=25 \mathrm{~s}$ and $U=37 \mathrm{kN}$. c, d $F=15 \mathrm{kN}, T=90 \mathrm{~s}$ and $U=$ $27 \mathrm{kN}$
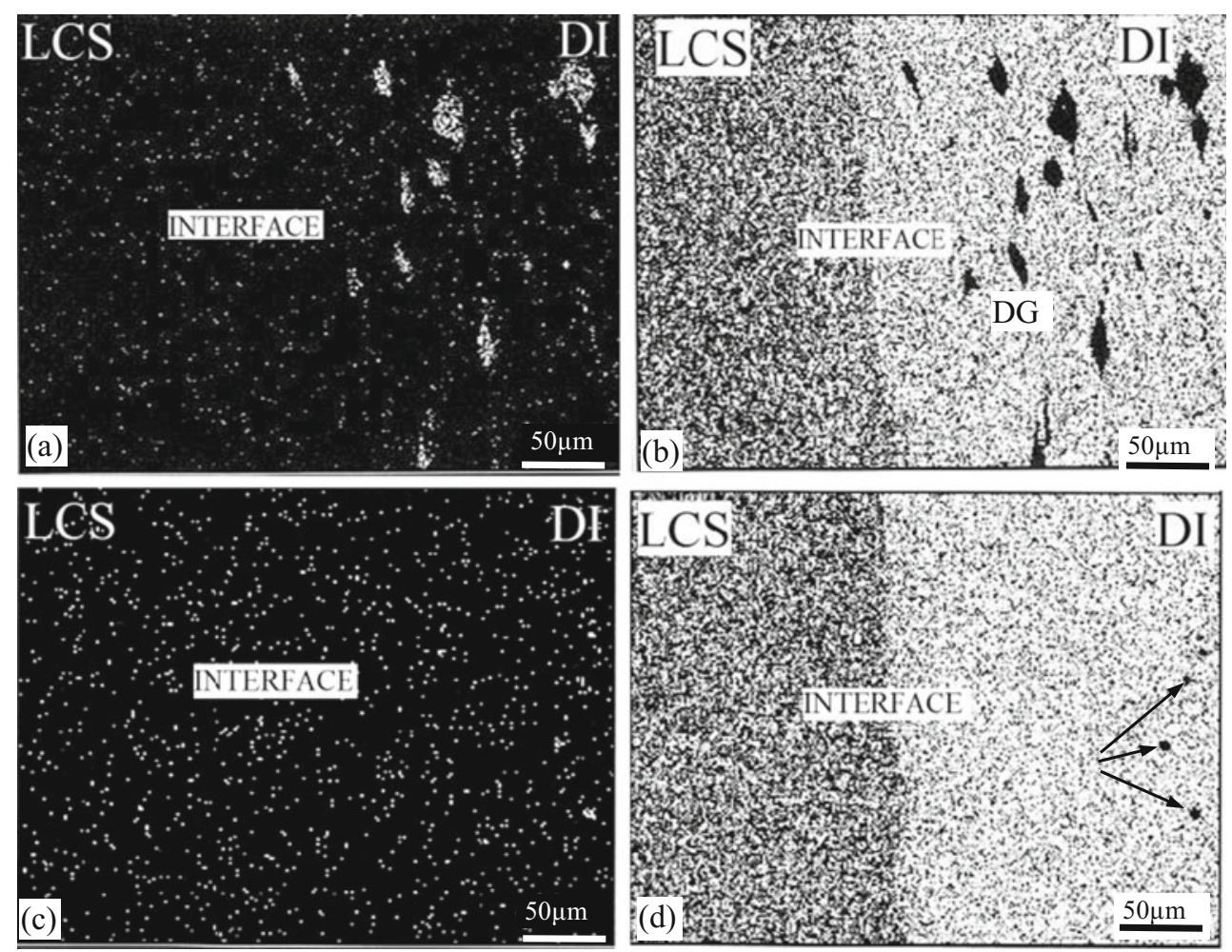


\section{Conclusions}

The following important conclusions are obtained from this study:

1. An empirical relationship was developed to predict the ultimate tensile strength of the friction-welded LCS-DI rods incorporating at $95 \%$ confidence level. A maximum tensile strength of $482 \mathrm{MPa}$ could be obtained under the welding conditions of friction force of $15 \mathrm{kN}$, upset force of $27 \mathrm{kN}$ and friction time of $90 \mathrm{~s}$.

2. The plots indicate that the friction time is a strong determinant in changing tensile strength followed by upset force and friction force. Tensile strength is found to decrease with an increase in friction time, reaches a minimum and then increases rapidly. Upset force has a negative effect on the tensile strength joints. As upset force increases, the tensile strength decreases.

3. The metallographic study showed that a diffusion of carbon occurs from the ductile iron to the low carbon steel. This process causes the formation of a carbon-rich zone at the interface and decarburization zone in the ductile iron close to the bond interface. The diffusion of carbon into steel favours the partial dissolution of graphite nodules during friction welding and their renewed spheroidization to obtain less energetic morphologies.

4. The Vickers hardness of the weld zone increased to $71 \%$ for DI and $44 \%$ for LCS of the base metals, respectively. This is a very small variation comparing with the other fusion welding process.

5. The results of the EDS show obviously that the friction welding process was accompanied by a diffusion of carbon atoms from ductile iron to steel. This leads to an increase of carbon concentration in steel.

Acknowledgments The author wishes to thank Professor Mieczysław Kaczorowski from the Institute of Mechanics and Design of Warsaw University of Technology and Stanisław Dymski from the Faculty of Mechanics of Bydgoszcz Technical University for their valuable contributions.

Open Access This article is distributed under the terms of the Creative Commons Attribution 4.0 International License (http:// creativecommons.org/licenses/by/4.0/), which permits unrestricted use, distribution, and reproduction in any medium, provided you give appropriate credit to the original author(s) and the source, provide a link to the Creative Commons license, and indicate if changes were made.

\section{References}

1. Davis JR (1996) ASM speciality handbook: cast irons. ASM International, Metals Park, OH, USA

2. Handbook W (1991) Welding process, vol 2, 8th-ed. AWS, Miami

3. Handbook ASM (1992) Metallography and microstructures, vol 9. ASM International, Metals Park, OH, USA
4. Handbook ASM (1995) Properties and selection iron and steel, vol 1. ASM International, Materials Park, OH, USA

5. Pascual M, Cembrero J, Salas F (2008) Analysis of the weldability of ductile iron. Mater Lett 62:1359-1362

6. Klimpel A (1998) The problem of welding cast irons is examined taking the example of a spheroidal cast iron. Weld Int 12(1):20-24

7. El-Banna EM (1999) Effect of preheat on welding of ductile cast iron. Mater Lett 41:20-26

8. Crossland B (1971) Friction welding. Contemp Phys 12(6):559574

9. American Welding Society (1989) Specifications and standards. In: Recommended practice for friction welding, AWS, Miami

10. Lebedev VK, Chernenko IA (1992) Welding and surface reviews friction welding. Harwood Academic Publishers, Amsterdam

11. Mitelea I, Craciunescu CM, Gugu R (2010) Interfacial behavior of dissimilar friction welded nodular cast irons with low carbon steels. Mater Sci For 638-642:3757-3762

12. Richter H, Palzkill A (1985) Applicability of test result from miniature friction welded specimens to full-size specimens as demonstrated by the combination of constructional steel and spheroidal graphite cast iron. Weld Cutt 37:60-5

13. Dette M, Hirsch J (1990) Reibschweissen von Konstruieren aus Kugelgraphitguss mit Stahlteilen. Schw und Schn 11(42):188-190

14. Michiura Y, Maekawa K, Takahara W, Kitagawa M, Horie H (1998) Friction welding of ductile cast iron pipes. Jpn J Foundry Eng Soc 70:873-877

15. Shinoda T, Endo S, Kato Y (1999) Friction welding of cast iron and stainless steels. Weld Int 13(2):89-95

16. Ochi H, Kawai G, Morikawa K, Yamamoto Y, Suga Y (2007) Macrostructure and temperature distribution near the weld interface in friction welding of cast iron. Strength Fract Compl 5:79-88

17. Song Y, Liu Y, Zhu X, Yu S, Zhang Y (2008) Strength distribution at interface of rotary-friction-welded aluminium to nodular cast iron. Trans Nonf Met Soc China 18:14-18

18. Winiczenko R, Kaczorowski M (2012) Friction welding of ductile cast iron using interlayers. Mater Des 34:444-451

19. Winiczenko R, Kaczorowski M (2013) Friction welding of ductile iron with stainless steel. J Mater Process Technol 213:453-462

20. Handbook ASM (2010) Metals process simulation, vol 22b. ASM International, Materials Park, OH, USA

21. Deb K (1998) Optimization for engineering design. Prentice-Hall, New Delhi

22. Montgomery DC (2009) Design and analysis of experiments, 7edth edn. Wiley, New York

23. ASTM E8 M-04 (2010) Standard test methods for tension testing of metallic materials. ASTM International

24. Design-Expert Software (2009) Version 8.0 user's guide

25. Murti KG, Sundaresan S (1983) Parameter optimization in friction welding dissimilar materials. Met Construct 331-335

26. Canyurt $\mathrm{O}$ (2005) Estimation of welded joint strength using genetic algorithm approach. Int J of Mech Sci 47:1249-1261

27. Paventhan R, Lakshminarayanan PR, Balasubramanian V (2011) Prediction and optimization of friction welding parameters for joining aluminium alloy and stainless steel. Trans Nonf Met Soc China 21:1480-148

28. Sathiya $\mathrm{P}$ (2009) Optimization of friction welding parameters using evolutionary computational techniques. J Mater Process Technol 5: 2576-2584

29. Kumaran SS, Muthukumaran S, Vinodh S (2010) Optimization of friction welding of tube to tube plate using an external tool. Struct Multidisc Optim 42(3):449-457

30. Kumaran SS, Muthukumaran S, Vinodh S (2011) Optimization of friction welding of tube-to-tube plate using an external tool by Taguchi method and genetic algorithm. Int J Adv Manuf Technolo 57:167-182 
31. Dey V, Pratihar DK, Datta GL, Jha MN, Saha TK, Bapat AV (2009) Optimization of bead geometry in electron beam welding using a genetic algorithm. J Mater Process Technol 209:1151-7

32. Padmanaban G, Balasubramanian V (2010) Prediction of tensile strength and optimization of process parameters for friction stir welded AZ31B magnesium. Proceed Inst Mech Eng, Part B: J of Eng Manuf 10(224):1519-1528

33. Babu S, Elangovan K, Balasubramanian V, Balasubramanian M (2009) Optimizing friction stir welding parameters to maximize tensile strength of AA2219 aluminum alloy joints. Met Mater Int 15:321-330

34. Bilgin MB, Meran C, Canyurt OE (2013) Optimization of strength of friction welded joints for AISI 430 ferritic stainless steels by genetic algorithm. Int J Adv Manuf Technolo 73:doi 10.1007/ s00170-014-6590-0

35. Elangovan S, Anand K, Prakasan K (2012) Parametric optimization of ultrasonic metal welding using response surface methodology and genetic algorithm. Int J Adv Manuf Technolo 63:561-572

36. Winiczenko R, Sałat R, Awtoniuk M (2013) Estimation of tensile strength of ductile iron friction welded joints using hybrid intelligent methods. Trans Nonf Met Soc China 23(2):385-391

37. Udayakumar T, Raja K, Afsal Husain TM, Sathiya P (2014) Prediction and optimization of friction welding parameters for super duplex stainless steel (UNS S32760) joints. Mater Des 53:226235

38. Deb K (2001) Multi-objective optimization using evolutionary algorithms. John Wiley and Sons, Ltd., England

39. Gen M, Cheng R (2000) Genetic algorithm and engineering optimization. John Wiley \& Sons, Inc.

40. Goldberg DE (1989) Genetic algorithm in search, optimization and machine learning. Addison-Wesley, Reading

41. Ellis CRG (1972) Continuous direct drive friction welding of mild steel. Weld Res Suppl 4:183-197

42. Kurt A, Uygur I, Paylasan U (2011) Effect of friction welding parameters on mechanical and microstructural properties of dissimilar AISI 1010-ASTM B22 joints. Weld J 90:102-106

43. Winiczenko R, Kaczorowski M (2015) Friction welding of ductile irons. In: Colás R and Totten GE (ed) Encyclopedia of iron, steel, and their alloys, 1st edn. Francis \& Taylor Group, New York (accepted)

44. Sahin M (2009) Joining of stainless-steel and aluminium materials by friction welding. Int J Adv Manuf Technolo 41:487-497

45. Sahin M (2010) Joining of aluminium and copper materials with friction welding. Int J Adv Manuf Technol 49:527-534

46. Cheng CP, Lin HM, Lin JC (2010) Friction welding of ductile iron and low carbon steel. Sci Technol Weld Join 15(8):706-711

47. Fujii H, Cuia L, Tsuji N, Maeda M, Nakata K, Nogi K (2006) Friction stir welding of carbon steels. Mater Sci Eng A 429(1-2), 15:50-57

48. Nguyen TC, Weckman DC (2006) A thermal and microstructure evolution model of direct-drive friction welding of plain carbon steel. Metall and Mater Trans B 37(2):275-292

49. Sathiya P, Aravindan S, Noorul Haq A (2007) Effect of friction welding parameters on mechanical and metallurgical properties of ferritic stainless steel. Int J Adv Manuf Technol 31:1076-1082

50. Chang HT, Wang CJ, Cheng CP (2014) Microstructure feature of friction stir butt-welded ferritic ductile iron. Mater Des 56:572-578

51. Baker H (1990) Alloy phase diagram, vol 3. ASM Handbook, Materials Park, Ohio

52. Shamanian M, Mousavi Abarghouie SMR, Mousavi Pour SR (2010) Effects of surface alloying on microstructure and wear behavior of ductile iron. Mater Des 31:2760-2766

53. Benyounis KY, Fakron OMA, Abboud JH, Olabi AG, Hashmi MJS (2005) Surface melting of nodular cast iron by Nd-YAG laser and TIG. J Mater Process Technol 170:127-13220

54. Pouranvar M (2010) On the weldability of grey cast iron using nickel based filler metal. Mater Des 31(7):3253-3258

55. Calvo FA, Urena A, Gomez de Salzar JM, Molleda F (1989) Diffusion bonding of grey cast iron to Armco iron and a carbon steel. J Mater Sci 24(11):4152-4159

56. Dieter GE (1986) Mechanical metallurgy. McGraw-Hill Co., New York

57. Askari-Paykani M, Shayan M, Shamanian M (2014) Weldability of ferritic ductile cast iron using full factorial design of experiment. J Iron Steel Res Int 21(2):252-263 